\title{
The Inflation Paradox in China and Its Reason
}

\author{
Song Chen* \\ Tan Kan Kee College, Xiamen University, Fujian Province, China, 363105 \\ chensong@xujc.com
}

Keywords: CPI; GDP Deflator; Lnflation Paradox

\begin{abstract}
Theoretically speaking, there are two methods to calculate the inflation: CPI and GDP deflator. Although these two methods might have different results, the difference would be normally very slight and the calculation based on CPI tends to get higher inflation rates than the one based on GDP deflator. However, the Chinese inflation is paradoxical to the above normal result. Specifically, the results from two methods are hugely different and the calculation based on CPI is far less than the one based on GDP deflator. This paper aims to discuss the possible reasonS for these paradoxical results in China. Researchers assert that it is the exclusive of the household price and rental price that play the most important role in these paradoxical results.
\end{abstract}

\section{Introduction}

The importance of inflation data has been emphasized by economists for a long time. The inflation is not only an economic indicator for macroeconomic performance of a specific country but also the cornerstone for the analysis of economic topics, such as Phillip's curve [1].

Basically, there are two inflation calculation methods: GDP deflator and CPI [2]. Although these two methods might have different results, the difference would be normally very slight and the calculation based on CPI tends to get higher inflation rates than the one based on GDP deflator [3, 4, 5]. This paper aims to discuss the possible reasons for these paradoxical results in China. Researchers assert that it is the exclusive of the household priceand rental price that play the most important role in the explanation of these paradoxical results. Researchers also stimulate a utopia economy, in order to judge whether the possibility have this paradoxical result or not by taking our explanation into consideration.

The paper is organized as follows. The next section shows the empirical results regarding G7 countries. After that, researchers will show the paradoxical result in China and then give our explanation for that result, and the fourth section draws concludes conclusion.

\section{Inflation Rate of G7 countries}

According to Mankiw [2], there are normally two methods for inflation calculation: GDP deflator or CPI. Although these two methods might have different results, the difference would be normally very slight and the calculation based on CPI tends to get higher inflation rates than the one based on GDP deflator.

In order to show the normal results demonstrated above, researchers would like to show in Fig. 1 the inflation of G7 countries: US, Canada, Japan, England, German, France and Italy. The inclusion of the inflation rate of China here is to show its extraordinary result and the detailed calculation will be further explained in the next section. Based on the data from G7 countries, it is shown from Fig. 1 that the real data is consistent with the economic anticipation [6]. 

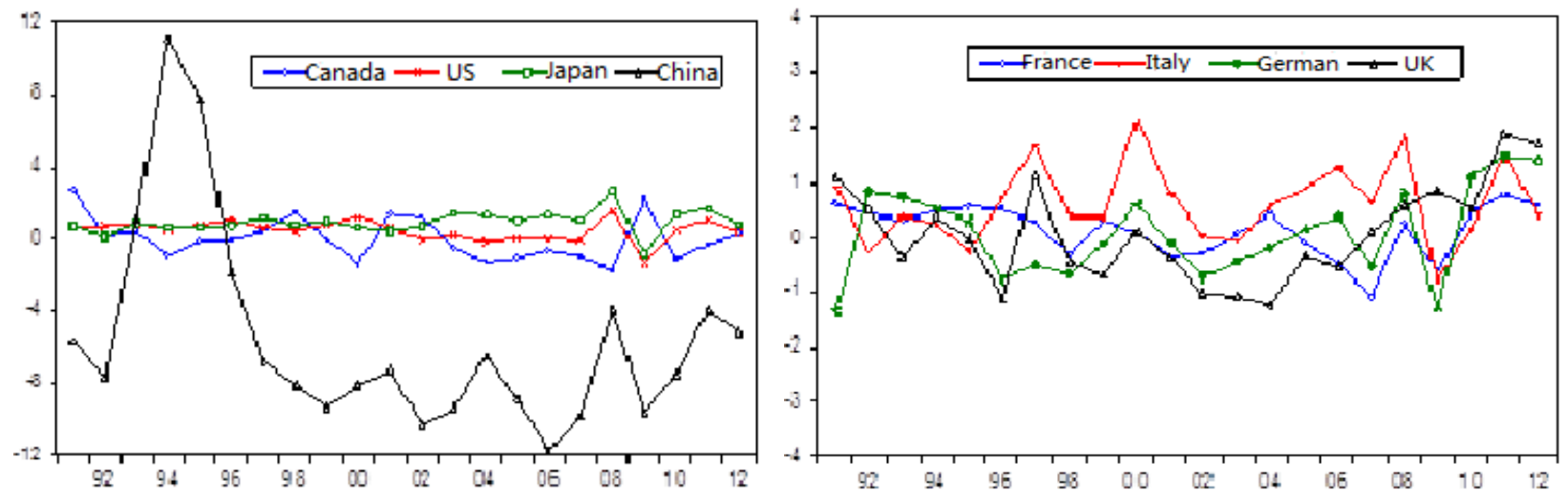

Fig. 1 Inflation of G7 Countries Calculated by Using CPI

Note: The data of US is from http://www.usa.gov/Topics/Reference-Shelf/Data.shtml and www.economagic.com. The Japan data comes from http://www.stat.go.jp/english/index.htm. The data of other five countries comes from http://stats.oecd.org/. Except Japan, the time period of other six countries is from 1991-2011. The data of China comes from the China Statistic Yearbook.

From Fig. 1, it is clearly shown that most countries have a higher inflation rate when calculated by using CPI than by using GDP deflator. Following [7, 8, 9], in order to make further comparison, researchers define the difference of results obtained by those two methods as follows:

$$
\begin{array}{cc}
I(\operatorname{diff}(C P I-D e f))=1, & \operatorname{diff}(C P I-D e f) \geq 0 \\
I(\operatorname{diff}(C P I-D e f))=-1, & \operatorname{diff}(C P I-D e f)<0
\end{array}
$$

Where, diff(CPI-Def) is the inflation difference calculated by using CPI and GDP deflator, and I( $\bullet$ ) is the value definitiom, and if $\operatorname{diff}(\mathrm{CPI}-\mathrm{Def}) \geq 0$ then $\mathrm{I}=1$, and if $\operatorname{diff}(\mathrm{CPI}-\mathrm{Def})<0$, then $\mathrm{I}=-1$. By using the definition function, researchers can further calculate the sum of the difference as

$$
S=\sum_{i=1991}^{2011} I[\operatorname{diff}(C P I-D e f)]
$$

The result of the sum of the differenc over the sample years can be summarized as the following table.

Table 1 The Sum and the Average of the Inflation DifferenceInflation

\begin{tabular}{|c|c|c|c|c|c|c|c|c|}
\hline & USA & Japan & England & France & German & Italy & Canda & China \\
\hline S & 11 & 17 & -1 & 7 & 13 & -1 & -5 & -15 \\
\hline AVG & $0.59 \%$ & $0.88 \%$ & $0.69 \%$ & $0.43 \%$ & $0.76 \%$ & $0.66 \%$ & $0.97 \%$ & $7.54 \%$ \\
\hline
\end{tabular}

On the other hand, in order to see the difference between inflations by two methods, researchers define the average of the difference as:

$$
A V G=\frac{\sum|\operatorname{diff}(C P I-D e f)|}{n}
$$

Where, $n=21$, it excludes Japan that only covers 19 years $(n=19)$. The summary of the average difference in inflation calculated by two methods can be seen in table 1. From table 1 and Fig. 1, it is obvious that except Canada, England and Italy, other four countries have higher inflation rate 
calculated by CPI than by GDP deflator. The special case is Canada, because the inflation rate calculated by CPI is higher than the one by GDP over the past 8 years.

The most obviously common feture of the inflation rate from G7 countries is that the abosolute value of the difference between inflation rates calculated by two different methods are small. More specifically, even though Canada has witnessed the largest absolute value of the inflation rate, the value is only less than $1 \%(0.97 \%)$.

\section{Inflation Paradox in China}

Based on the statistics from the China Statistic Yearbook, researchers can calculate the China's inflation rate as the following Fig. 2.

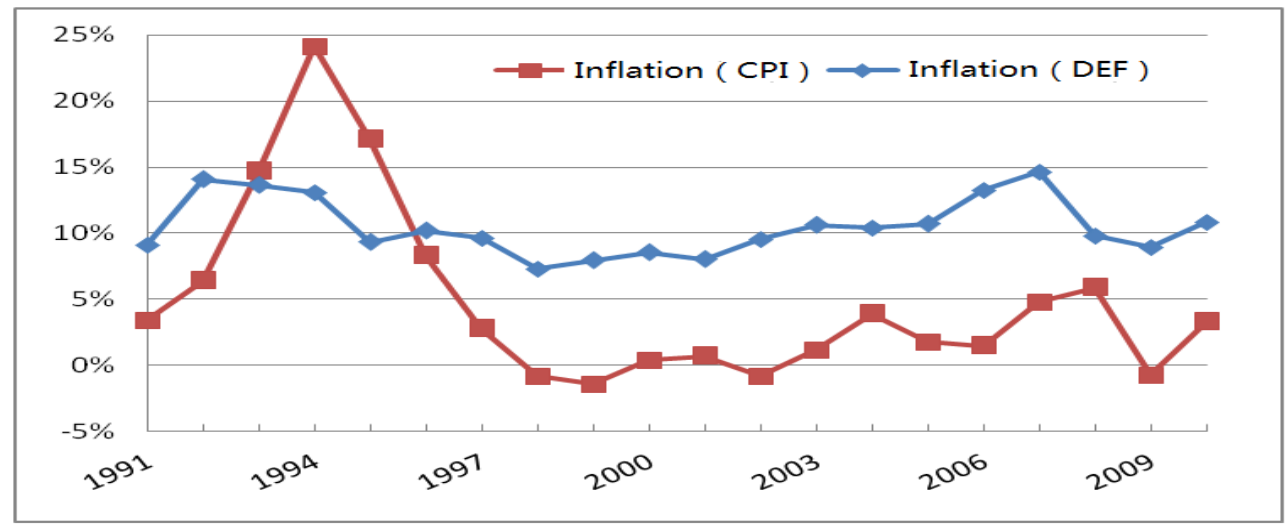

Fig. 2 China's Inflation Calculated by Using CPI and GDP Deflator

According to the above figure, the inflation rate calculated by using GDP is always higher than the one calculated by using CPI, except the years from 1993-1995. The second feature of the trend between GDP deflator and CPI is also quite obvious, that is, the inflation rate calculated by the former method is higher than the one by the latter method, which is the most distinguished result the differentiating China from G7 countries, as shown in Fig. 1.

From the results summarized in Table 2, the inflation rate of G7 countries by two methods are only $0.97 \%$. However, the inflation of China is paradoxical to the above normal result. Specifically, the average result obtained by the former method is about $7.54 \%$ higher than the one obtained from the later method. Those results are so different from the ones obtained in G7 countries that it is called inflation paradox.

\section{Explanation for the Inflation Paradox in China}

According to the explanation of inflation calculation in China Statistic Yearbook, the sample covers eight sections and 262 divisions, and over 600 kinds of goods are surveyed. From it, researchers can tell that the household price is not included in inflation calculation. Howerver, on the other hand, the household price fluctuated a lot since 1998 when China implemented the "Monetarilization of household distribution". Therefore, it is expectable that the inflation rate calculated by using CPI could be very different if household price is included.

In the utopia economy as researchers assumed, there are five products: apple, orange, household, coffee and concrete. For simplicity, researchers assume that consumers only purchase apples, oranges, coffee and household. The purchase of concrete is government consumption. Also, the orange and apple are substitutional to each other.

After that, researchers define the first year of inflation calculation as the initial year, the market price of those goods is 100, and there are 100 units for each goods. Then, researchers can manipulate the data 
of five products as the information, as given in Table 4. The inflation rate of the utopia economy during eleven years are calculated by setting the weight for household price as $40 \%$, and the Fig. 3 summarizes the changing trend of inflation rate of the utopia economy.

Fig. 3 Inflation Rate Calculated by CPI and GDP Deflator in the Utopia Economy

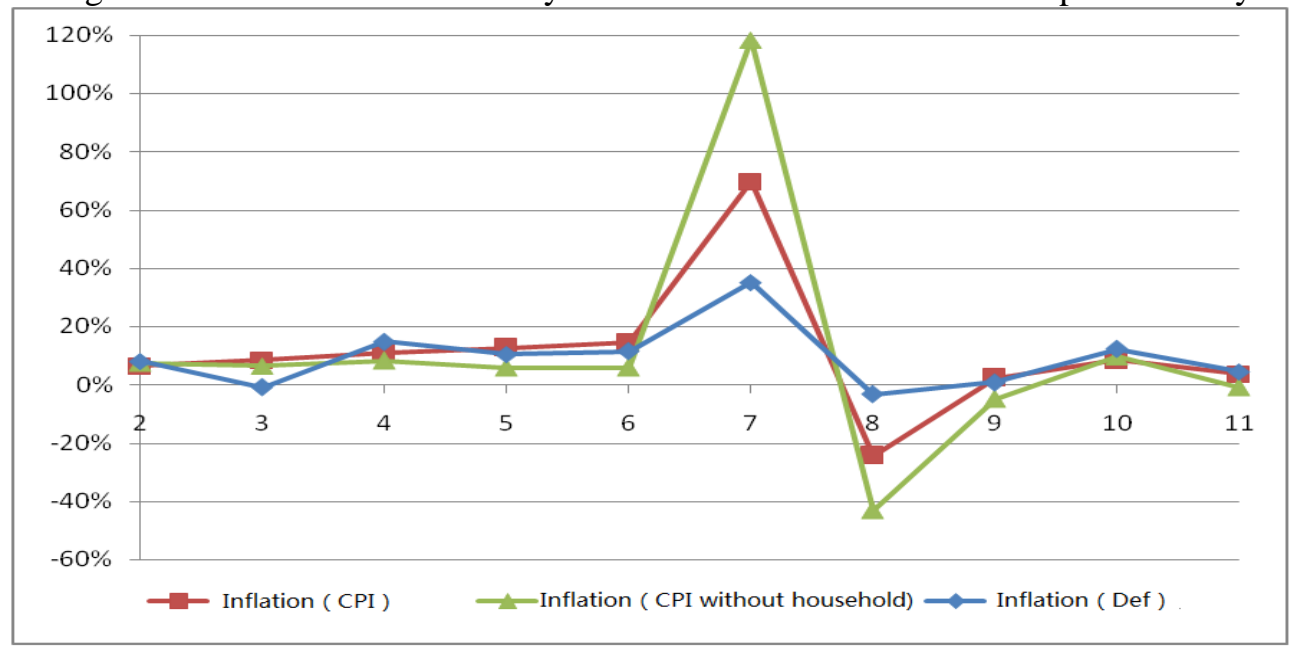

Fig. 3 shows that if CPI includes the prices of all products, then the inflation rate by CPI is generally higher than the rate by GDP deflator, which is consistent with the results obtained in G7 countries. When there is a sharp increase in the household price, the inflation rate calculated by CPI without household purchase could be always lower than the inflation rate calculated by GDP deflator. Another interesting feature of Fig. 3 is that in the seventh year of the utopia economy, the CPI-based inflation rate tends to overestimate the living cost, because CPI does not consider the substitution effect between orange and apple.

Table 2 Inflation Rate Calcualted for the Utopia Economy

\begin{tabular}{|c|c|c|c|c|c|}
\hline $\begin{array}{c}\text { Average Infaltion } \\
\text { Rate } \\
\text { (GDP-based) }\end{array}$ & $\begin{array}{c}\text { Average } \\
\text { Inflation Rate } \\
\text { (CPI-based) }\end{array}$ & $\begin{array}{c}\text { Avarage Inflation Rate } \\
\text { (CPI-based without } \\
\text { household) }\end{array}$ & $\begin{array}{c}\text { S (household Price } \\
\text { Excluded) }\end{array}$ & AVG \\
\hline $9.31 \%$ & $11.22 \%$ & $11.28 \%$ & 0 & -6 & $8.16 \%$ \\
\hline
\end{tabular}

From Table 2, it is clear that when the household price is excluded from CPI index, the inflation rate based on CPI is always lower than the rate based on GDP deflator. Furthermore, the S value without household price is -6 , which means that during most of the years, the inflation based on CPI without household price will be lower than the rate calculated on GDP deflator-a result consistent with the China data. Except that, the average of the absolute difference value of inflation rate between two methods is only $3.23 \%$, which indicates that the assumed economy with only five products has a very satisfactory feature.

\section{Summary}

This paper firstly demonstrated the commonly used two methods of inflation calculation and applied those methods to calculate the inflation rate of $G 7$ countries. The results of $G 7$ countries show that the inflation calculated by using CPI is only slightly different from the one by using GDP deflator. Secondly, by applying the same methods to calculate the inflation in China, the results showed that the average difference between two methods is around $7.54 \%$ or higher. The analysis showed that the huge difference is partly due to the exclusion of the household price and rental price. Consequently, it is 
believed that inflation data based on the GDP deflator would be a better indicator of the real change in the price of China than CPI.

\section{References}

[1] M.D. Shapiro, and D.W. Wilcox, Mismeasurement in Consumer Price Index: an Evaluation, Working Paper, NBER (1996).

[2] N.G. Mankiw, N.G., Macroeconomics, 7th Edition, Worth Publishers, New York, 2010.

[3] W. C. Randolph, 1988. Housing Depreciation and Aging Bias in the Consumer Price Index, Journal of Business and Economic Statistics, 6(1988) 359-371.

[4] B.R. Moulton, Basic Components of the CPI: Estimation of the Price Changes, Monthly Labor Review, 116(1993) 13-24.

[5] D. Fixler, The Consumer Price Index: Underlying Concepts and Caveats, Monthly Labor Review, 116(1993) 3-12.

[6] A. M. Aizcorbe and C.J. Patrick, The Commodity Substitution Effect in CPI Data, 1982-1991, Monthly Labor Review, 116(1993) 25-33.

[7] J.E. Triplett, Price Index Research and Its Influence on Data: a Historical Review, Mimeo, Bureau of Economic Analysis, (1988).

[8] M.D. Shapiro and W.W. David, Calculating the Distribution of the Total Bias in the Consumer Price Index, NBER Working Paper, (1996).

[9] M. Reinsdorf, The Effect of Outlet Price Differentials on the US Consumer Price Index, in M.Foss, M. Manser, and A.Young, (Eds.), Price Measurements and Their Uses, NBER Studies in Income and Wealth, 57(1993). Chicago: University of Chicago Press.

[10] T. Unayama, Upward Bias in the Consumer Price Index under the Zero-inflation Economy, Economic Letters, 85(2004) 139-144. 